\title{
The effect of exercise on regional adipose tissue and splanchnic lipid metabolism in overweight Type 2 diabetic subjects
}

\author{
L. Simonsen ${ }^{1}$ - O. Henriksen ${ }^{1}$ L. H. Enevoldsen ${ }^{1}$ J. Bülow ${ }^{1}$ \\ ${ }^{1}$ Department of Clinical Physiology, Bispebjerg Hospital, University of Copenhagen, Copenhagen NV, Denmark
}

\begin{abstract}
Aims/hypothesis. To test the hypothesis that adipose tissue lipolysis is enhanced in patients with Type 2 diabetes mellitus, we examined the effect of exercise on regional adipose tissue lipolysis and fatty acid mobilisation and measured the acute effects of exercise on the co-ordination of adipose tissue and splanchnic lipid metabolism.

Methods. Abdominal, subcutaneous adipose tissue and splanchnic lipid metabolism were studied by conducting measurements of arterio-venous concentrations and regional blood flow in six overweight Type 2 diabetic subjects before, during and after exercise.

Results. Exercise induced an increase in adipose tissue lipolysis and fatty acid release. However, the increase in adipose tissue blood flow was small, limiting fatty acid mobilisation from this tissue. Some of the fatty acids were released in excess in the post-exercise phase. The splanchnic fatty acid uptake was un-
\end{abstract}

changed during the experiment but splanchnic ketogenesis increased in the post-exercise phase. The arterial glucose concentration decreased during exercise and continued to decrease afterwards, indicating an imbalance between splanchnic glucose production and whole-body glucose utilisation.

Conclusions/interpretation. Regional subcutaneous, abdominal adipose tissue lipolysis is no higher in patients with Type 2 diabetes than in young, healthy subjects. Exercise stimulates adipose tissue lipolysis, but due to an insufficient increase in blood flow, a high fraction of the fatty acids liberated by lipolysis cannot be released to the blood. Splanchnic glucose release is smaller than whole-body glucose utilisation during exercise and post-exercise recovery.

Keywords Blood flow - Glycerol - Lipolysis · Liver · Fatty acids $\cdot$ Splanchnic metabolism $\cdot$ Splanchnic tissues $\cdot$ Subcutaneous adipose tissue $\cdot$ Type 2 diabetes
Received: 13 October 2003 / Accepted: 26 January 2004

Published online: 17 March 2004

(C) Springer-Verlag 2004

J. Bülow $(\bowtie)$

Department of Clinical Physiology, Bispebjerg Hospital, University of Copenhagen, 2400 Copenhagen NV, Denmark E-mail: jb04@bbh.hosp.dk

Tel.: +45-3531-2806, Fax: +45-3531-3954

Abbreviations: ICG, indocyanine green .

3-OHB, 3-hydroxybutyrate · TAG, triacylglycerol .

$\mathrm{VO}_{2 \text {,max }}$, peak oxygen consumption

\section{Introduction}

One characteristic of Type 2 diabetes mellitus is disturbances in fatty acid metabolism and glucose metabolism. The utilisation of plasma fatty acids is impaired in obese Type 2 diabetic patients [1] while it seems to be normal in non-obese Type 2 diabetic patients during exercise [2]. When measured at rest, the plasma concentration of fatty acids is usually elevated in Type 2 diabetic patients. This has in part been ascribed to insulin resistance in adipose tissue, which results in an increased lipolytic rate because the inhibitory effect of insulin on hormone-sensitive lipase activity is reduced [3]. The increased fatty acid concentration leads to an increased fatty acid supply to the 
liver. It has, moreover, been suggested that fatty acids play a key role in the regulation of hepatic glucose metabolism, thereby increasing glucose production [4]. During exercise, the glucose concentration in Type 2 diabetic patients decreases steadily, so glucose production does not match utilisation in this situation, a fact thought to be due either to an insufficient increase in production $[5,6]$ or to enhanced utilisation $[7,8,9]$. During prolonged exercise of moderate intensity, adipose tissue lipolysis and the release of fatty acids increase in normal healthy subjects [10]. This is primarily due to an increased sympathetic adrenergic activity concomitant with reduced insulin concentrations. Furthermore, fatty acid mobilisation is increased to a greater extent than fatty acid utilisation, leading to higher arterial fatty acid concentrations. In insulinresistant subjects this increase could be intensified, which would cause an increased supply of fatty acids to the liver, provided that splanchnic perfusion is not reduced excessively during exercise.

Only few studies of lipid metabolism in patients with Type 2 diabetes mellitus have been done during exercise, and adipose tissue lipid metabolism has to our knowledge never been measured directly in such subjects during and post-exercise. Simultaneous measurements of local adipose tissue and splanchnic tissues have also never been done in such patients. To test the hypothesis, therefore, that adipose tissue lipolysis is enhanced in patients with Type 2 diabetes mellitus, we examined the effect of exercise on regional adipose tissue lipolysis and fatty acid mobilisation and measured the acute effects of exercise on the co-ordination of adipose tissue and splanchnic lipid metabolism during exercise and in the post-exercise recovery period in overweight Type 2 diabetic subjects.

\section{Subjects and methods}

Subject characteristics. Six untrained, overweight (android type) Type 2 diabetic patients (five men, one woman) were studied. Two of the subjects were being treated with diet alone and four were being treated with sulfonylurea or metformin. Both drugs were discontinued for at least 3 days before the main experiment. The subjects gave their informed consent to participate in the study, which was conducted according to the Helsinki Declaration and approved by the local ethics committee of Copenhagen (project no. KF 11-90/02). Significant cardiovascular disease was excluded in all subjects by an exercise stress test. None of the subjects were taking medication affecting triacylglycerol (TAG) or fatty acid metabolism. Anthropometric and metabolic characteristics are given in Table 1.

Measurement of body composition. Body composition was determined by dual energy X-ray absorption scanning (Lunar DPX-IQ, software version 4.6c; Lunar Corporation, Madison, Wis., USA) using the medium scan mode and extended research analysis.

Determination of peak oxygen consumption. Prior to the exercise experiment the subjects performed a test to determine
Table 1. Anthropometric and metabolic characteristics of subjects studied

\begin{tabular}{lcc}
\hline Characteristic & Mean value & Range \\
\hline Age (years) & 63 & $57-70$ \\
Height $(\mathrm{cm})$ & 180 & $171-186$ \\
Weight $(\mathrm{kg})$ & 101 & $83-130$ \\
Fat $(\%)$ & 32.4 & $22.8-47.2$ \\
Fat $(\mathrm{kg})$ & 33.6 & $18.9-46.7$ \\
BMI & 31.0 & $25.6-38.4$ \\
C-peptide (pmol/l) & 742 & $531-2135$ \\
HbA c $(\%)$ & 7.0 & $5.1-9.9$ \\
Triglycerides (mmol/l) & 1.7 & $0.7-2.9$ \\
HDL (mmol/l) & 1.6 & $1.3-1.9$ \\
LDL (mmol/l) & 3.2 & $1.9-4.4$ \\
VLDL (mmol/l) & 0.8 & $0.3-1.3$ \\
\hline
\end{tabular}

their peak oxygen consumption $\left(\mathrm{VO}_{2, \max }\right)$. They exercised in a semi-recumbent position on an electrically braked cycle ergometer (Ergometrics er900L, Ergoline, Bitz, Germany). The initial workload was $30 \mathrm{~W}$, increasing by $30 \mathrm{~W}$ every 2 minutes until exhaustion. Oxygen uptake and carbon dioxide output were measured continuously with an Oxycon Champion System (Jaeger, Würzburg, Germany) using facemask and breath-by-breath technique. A 12-lead ECG was recorded continuously during the test and brachial blood pressure was measured every minute by auscultation.

Main experiment. The experiment started in the laboratory at 08.00 hours after an overnight fast. A catheter (Artflon; Ohmeda, Swindon, UK) was inserted into a radial artery of each subject during local analgesia obtained by local infiltration of $1.0 \mathrm{ml} 1 \%$ Lidocain. A subcutaneous, abdominal vein was catheterised during ultrasound/colour Doppler imaging of the vein as described previously [11]. A 22G 10-cm polyurethane catheter (Ohmeda) was inserted using the Seldinger technique. The right femoral vein was catheterised during local analgesia (Lidocain 1\%, 5-10 ml), and a polyethylene catheter (outer diameter $2.0 \mathrm{~mm}$ ) was advanced to a right-sided hepatic vein and left in position during the rest of the experiment. Catheterisation was done during fluoroscopic control. The catheters were kept patent throughout the experiment by continuous infusion of isotonic sodium chloride at a rate of $40 \mathrm{ml} / \mathrm{h}$. After the catheterisation procedures, a primed constant infusion of indocyanine green (ICG) $\left(1 \mathrm{mg} \cdot 170 \mu \mathrm{g}^{-1}\right.$ $\mathrm{min}^{-1}$ ) was begun. When steady-state arterial concentrations of ICG had been established, a 30-min basal control period began, in which three blood samples were drawn from the three catheters to determine basal resting metabolite concentrations. The subjects were then transferred to the bicycle ergometer and exercised for 60 minutes at $60 \%$ of peak oxygen uptake. After exercise the subjects were transferred back to the catherisation table where they were studied for another 3 hours during rest. During the pre- and post-exercise rest periods the subjects were in the recumbent position.

Whole-body measurements. Whole-body oxygen consumption and respiratory exchange ratio were measured by a ventilated hood system (Oxycon) in the pre- and post-exercise resting periods and by facemask and breath-by-breath technique during exercise. During the whole experiment continuous measurements of heart rate and intra-arterial blood pressure were performed by an Athena monitor (S\&W, Copenhagen, Denmark) interfaced to the Oxycon Champion system. 
Blood flow measurements. Blood flow through the abdominal subcutaneous adipose tissue was measured using a modification of the classical ${ }^{133} \mathrm{Xe}$-washout technique as recently described [12]. About $1 \mathrm{MBq}^{133} \mathrm{Xe}$ gas [13] was injected into the subcutaneous abdominal adipose tissue in the contralateral side of the catheter position. The washout of ${ }^{133} \mathrm{Xe}$ was measured by a scintillation counter system strapped to the skin surface above the region with the ${ }^{133} \mathrm{Xe}$ depot (Oakfield Instruments, Oxford, UK). The adipose tissue blood flow was calculated from the washout rate, assuming a tissue/blood partition coefficient value of $10 \mathrm{ml} / \mathrm{ml}$. Total hepatic blood flow (splanchnic blood flow) was measured by continuous infusion of ICG [14]. Blood samples for the determination of splanchnic plasma flow were drawn in triplicates (at 5-min intervals). In the middle of these periods blood samples were drawn for the measurement of metabolite concentrations. The plasma ICG concentration was determined by spectrophotometry at 805 and $904 \mathrm{~nm}$.

Blood sampling. Blood samples were drawn simultaneously from the catheters. Three samples were taken in the pre-exercise period and the average of these was used as the pre-exercise basal value. During exercise blood samples were drawn after 40 and 60 minutes of exercise. In the post-exercise period blood was drawn every 30 minutes for 3 hours. The blood was immediately deproteinised or collected in ice-cold vials, and the plasma was separated by centrifugation at $4{ }^{\circ} \mathrm{C}$. The samples were stored at $-20^{\circ} \mathrm{C}$ until analysis.

Analysis of hormone and metabolite concentrations. All analyses were performed in duplicate. Arterial insulin concentrations were determined using a commercial radioimmunoassay kit (NOVO Nordisk, Bagsvaerd, Denmark). Blood samples for the determination of oxygen content were taken anaerobically in heparinised syringes and stored on ice until analysis. Oxygen concentrations in arterial and hepatic venous whole blood were determined spectrophotometrically using an OSM 3 and/ or an ABL 725 (Radiometer, Copenhagen, Denmark). Glucose, lactate, 3-hydroxybutyrate (3-OHB) and glycerol concentrations were measured in neutralised perchloric extracts of whole blood and by standard fluorometric enzymatic methods, adapted to an IL Monarch Plus microcentrifugal analyser (Instrumentation Laboratory, Warrington, UK) [15]. Fatty acids concentrations were measured in duplicate in heparinised plasma with a commercial kit (Wako, Osaka, Japan), and total plasma TAG concentrations were measured as total glycerol concentrations after hydrolysis corrected for the free glycerol concentrations as previously described [15].

Calculations. Energy expenditure was calculated from oxygen uptake and respiratory exchange ratio [16]. Splanchnic plasma flow was calculated as previously described [15] and converted to whole blood flow after correction for haematocrit. Splanchnic oxygen consumption was calculated as the product of splanchnic blood flow and the differences in arterio-hepatic venous oxygen concentrations. Net metabolite fluxes from the subcutaneous adipose tissue and the splanchnic tissues were calculated by multiplying the arterio-venous (uptake) or the veno-arterial (output) difference in metabolite concentration by the appropriate blood or plasma flow (whole blood flow for the calculation of glycerol, glucose, 3-OHB and lactate fluxes; plasma flow for the calculation of fatty acids and TAG fluxes). The adipose tissue fatty acids:glycerol output ratio was calculated from the net fatty acids and glycerol outputs corrected for the contribution from intravascular lipolysis of TAG.

Statistics. All data are presented as means \pm SEM. The effects of time were analysed by two-way ANOVA (SPSS version 11.5). The post hoc test of significant changes between specific time points was performed by Dunnett's test. When testing the specific effect of exercise, the post-exercise data were not included in the analysis. A $p$ value of less than 0.05 was regarded as statistically significant.

\section{Results}

In the man weighing $130 \mathrm{~kg}$ it was technically impossible to catheterise a femoral vein. Thus results on splanchnic metabolism are based on five subjects, while those on adipose tissue were obtained in all six subjects.

Oxygen consumption and respiratory exchange ratio. The peak oxygen consumption was $2195 \pm 90 \mathrm{ml} / \mathrm{min}$ corresponding to $21.8 \pm 2.7 \mathrm{ml} \cdot \mathrm{kg}^{-1} \cdot \mathrm{min}^{-1}$. The mean values for oxygen uptake, respiratory exchange ratio and energy expenditure during the pre-exercise, exercise and 3-hour post-exercise periods are given in Table 2.

Blood concentrations. Arterial concentrations changed as follows (Table 3). The arterial glucose concentration decreased significantly during the whole experiment. The lactate concentration increased during exercise and decreased to pre-exercise values at $60 \mathrm{~min}$ post-exercise. Glycerol concentrations increased about 2.5 -fold during exercise but returned to the pre-exercise resting level $30 \mathrm{~min}$ after the end of exercise. Arterial fatty acids concentrations did not increase during exercise. However, $30 \mathrm{~min}$ after exercise they rose to values $40 \%$ higher than the pre-exercise value. At $60 \mathrm{~min}$ post-exercise fatty acids concentrations dropped to the pre-exercise level, remaining there for the rest of the experiment. The adipose tissue venous

Table 2. Oxygen uptake, respiratory exchange ratio and energy expenditure (means \pm SEM)

\begin{tabular}{lccccc}
\hline & Pre-exercise & $\begin{array}{l}\text { Exercise } \\
\left(60 \% \text { of } \mathrm{VO}_{2, \max }\right)\end{array}$ & $1 \mathrm{~h}$ post-exercise & $2 \mathrm{~h}$ post-exercise & 3 h post-exercise \\
\hline Oxygen uptake $(\mathrm{ml} / \mathrm{min})$ & $275 \pm 18$ & $1237 \pm 114$ & $300 \pm 15$ & $285 \pm 15$ & \\
RER & $0.79 \pm 0.02$ & $0.77 \pm 0.02$ & $0.76 \pm 0.01$ & $0.78 \pm 0.01$ & $290 \pm 14$ \\
EE $(\mathrm{kJ} / \mathrm{min})$ & $5.49 \pm 0.34$ & $24.61 \pm 2.26$ & $5.97 \pm 0.30$ & $5.69 \pm 0.29$ & $5.76 \pm 0.02$ \\
\hline
\end{tabular}

RER, respiratory exchange ratio; EE, energy expenditure; $\mathrm{VO}_{2 \text {, max }}$, peak oxygen consumption 

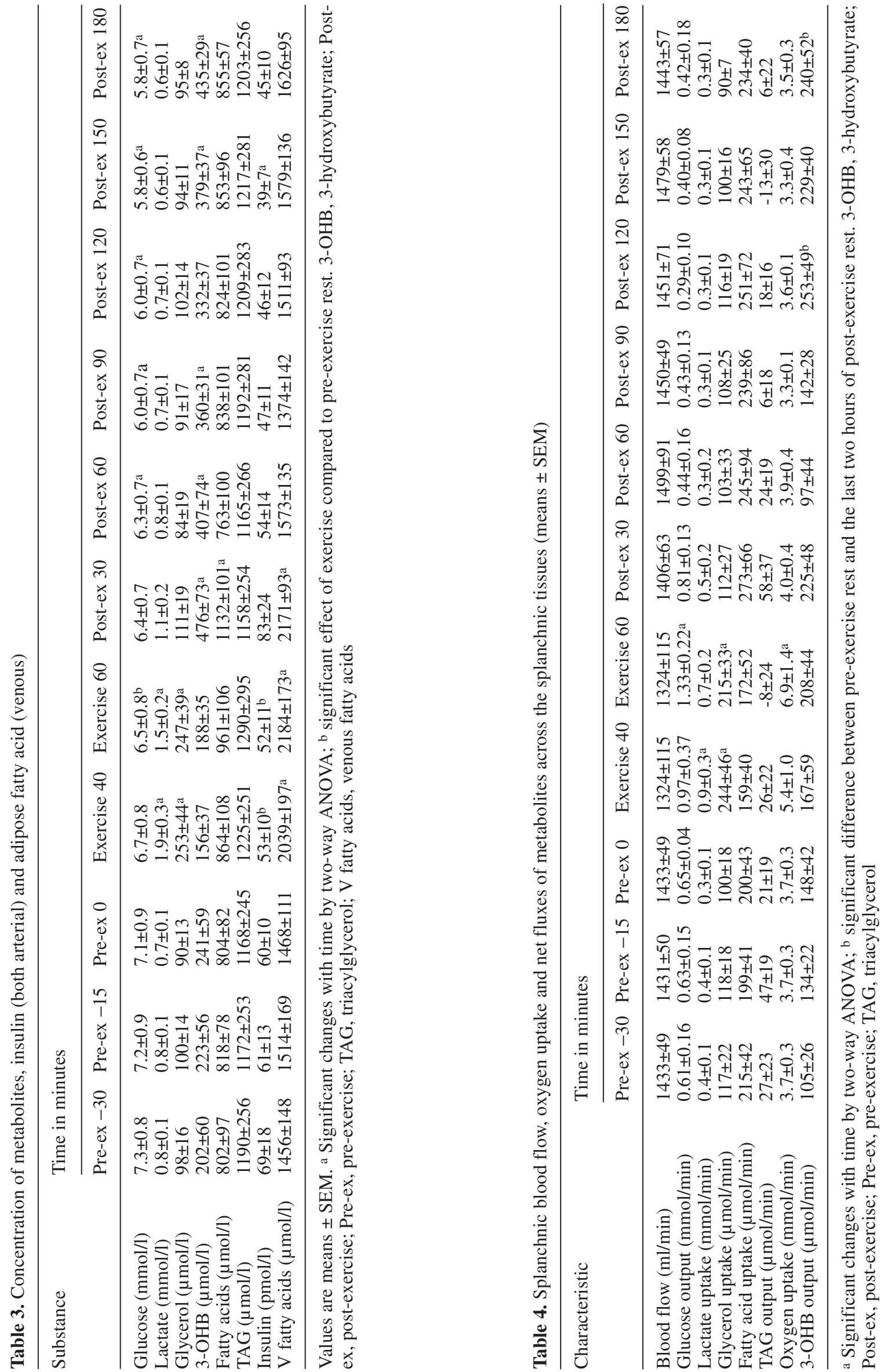

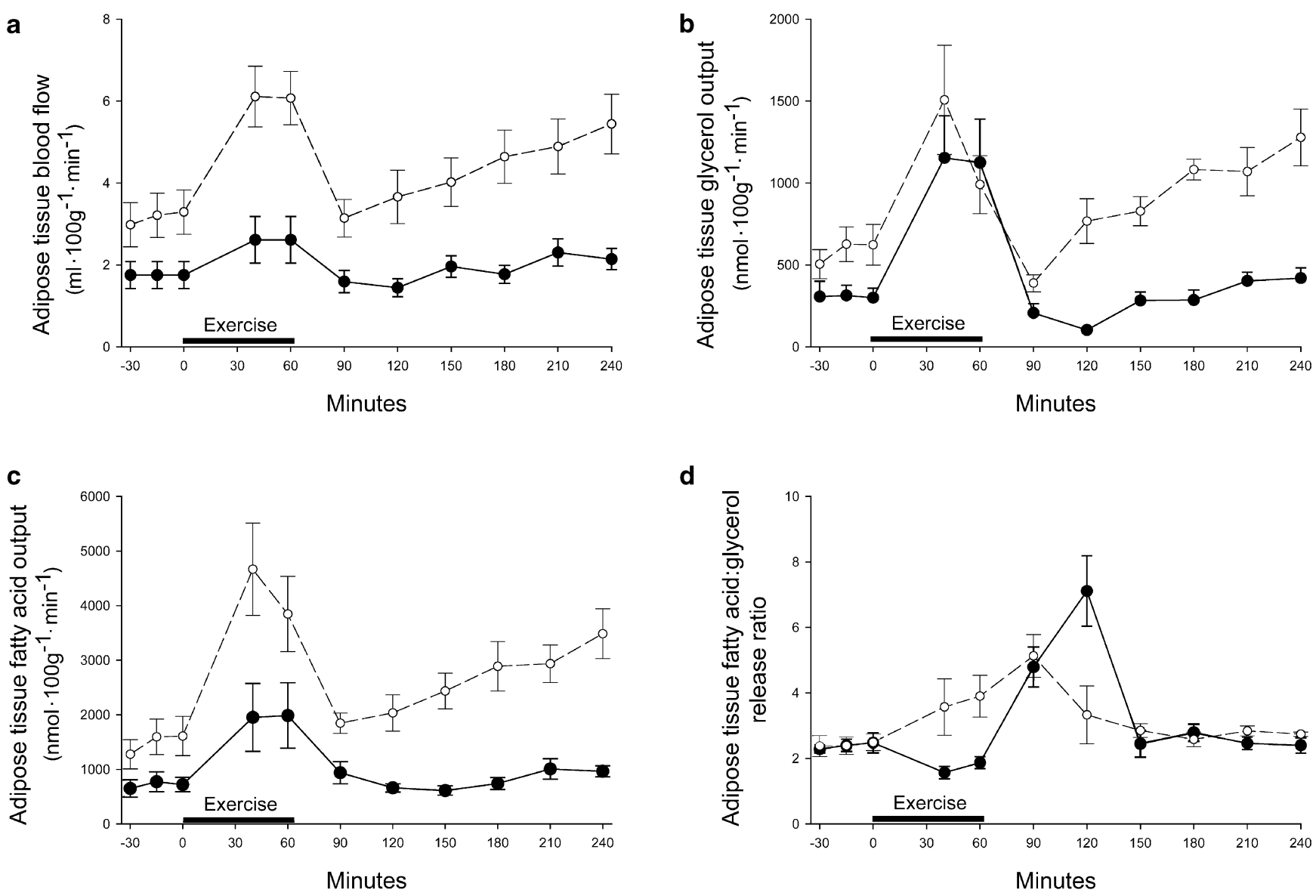

Fig. 1. Abdominal, subcutaneous adipose tissue metabolism in the pre-exercise rest, exercise and post-exercise rest periods. Results shown are (a) adipose tissue blood flow, (b) adipose tissue net glycerol output, (c) adipose tissue net fatty acid output and (d) adipose tissue fatty acid:glycerol release ratio. denotes results from Type 2 diabetic patients, $\bigcirc$ denotes previously published results for 9 young, healthy subjects [10, 17]. Values are means \pm SEM

concentration of fatty acids increased during exercise and 30 minutes post-exercise to mean values above $2 \mathrm{mmol} / \mathrm{l}$. The arterial TAG concentration did not change significantly during the experiment. Concentrations of 3-OHB did not change during exercise, but did increase about two-fold in the early post-exercise phase, staying increased for the rest of the experiment. The insulin concentration decreased both during exercise and in the post-exercise recovery period. An exception was the 30-min post-exercise period, where insulin concentrations increased about $60 \%$ against the exercise level.

Metabolic fluxes in abdominal, subcutaneous adipose tissue. Other results $[10,17]$ for adipose tissue metabolism in nine normal-weight, healthy subjects under identical experimental conditions are given as reference values for the results of the present study (Fig. 1). With regard to adipose tissue blood flow,

a small but significant increase was observed during exercise in abdominal, subcutaneous adipose tissue. Immediately after exercise the blood flow decreased to the pre-exercise level and remained at this level for the rest of the experiment (Fig. 1a). Net adipose tissue glycerol output (Fig. 1b) increased on average 4.4fold during exercise. It fell to the pre-exercise level 30 min after exercise and did not change during the remainder of the experiment. During exercise the fatty acids output (Fig. 1c) increased on average 2.9-fold, returning to the pre-exercise level $60 \mathrm{~min}$ after exercise and remaining at this level for the rest of the experiment. The fatty acids:glycerol release ratio (Fig. 1d) decreased from about 2.4 in the pre-exercise period to 1.8 during exercise, increasing to 4.8 and 7.1 at 30 and $60 \mathrm{~min}$ after exercise respectively. It then returned to the pre-exercise level for the remainder of the experiment. The net TAG uptake was $52 \pm 12 \mathrm{nmol} \cdot 100 \mathrm{~g}^{-1} \cdot \mathrm{min}^{-1}$ in the pre-exercise rest period. During exercise and post-exercise it was not significantly different from zero (data not shown).

Splanchnic metabolic fluxes. The splanchnic blood flow did not change significantly during the experiment (Table 4). Glucose output increased during exercise. However in the post-exercise period it was not significantly different from the pre-exercise output, although on average it was only about $50 \%$ of the preexercise level $(p=0.16)$ (these and other results in this 
paragraph; Table 4). It was not possible to show a significant change in splanchnic fatty acids uptake during the experiment. With regard to 3-OHB output, this increased significantly in the post-exercise period. The splanchnic lactate and glycerol uptake increased significantly during exercise, but both dropped to preexercise levels at $30 \mathrm{~min}$ post-exercise and remained there for the rest of the experiment. In contrast, it was not possible to show any significant change in splanchnic TAG output during the experiment. Splanchnic oxygen uptake was about $3.5 \mathrm{mmol} / \mathrm{min}$ (corresponds to $30 \%$ of whole-body oxygen uptake) in both rest periods. It increased about two-fold during exercise.

\section{Discussion}

The main findings of this study are:

1. The increase in subcutaneous, abdominal adipose tissue blood flow during exercise is impaired in untrained, obese patients with Type 2 diabetes mellitus, implying that the mobilisation of fatty acids from the tissue becomes restricted.

2. The lipolytic rate (per unit tissue weight) in abdominal, subcutaneous adipose tissue is neither increased in the resting fasting state, nor during exercise, when compared to that in young healthy subjects under comparable conditions.

3. Exercise at $60 \%$ of peak power output for 1 hour in the fasting state induces a steady decrease in the blood glucose concentration, which continues for at least 3 hours in the post-exercise recovery period.

Our experimental design has strengths and some weaknesses.

The main strength is that net fluxes of glycerol and fatty acids were measured directly and simultaneously in adipose tissue and in the splanchnic tissues. In most previous studies lipid metabolism has been extrapolated from whole-body measurements of rate of appearance of fatty acids and glycerol using isotope dilution techniques $[1,2,18]$ or from local measurements in adipose tissue using the microdialysis technique [19, $20,21]$. Both methods are encumbered with uncertainties. The glycerol measured using the isotope dilution technique originates from lipolysis in adipose tissues, skeletal muscles and circulating lipoproteins, and it is impossible to distinguish between these sources. Moreover, in studies where whole-body and local adipose tissue measurements were performed, the rate of appearance of glycerol and fatty acids was considerably higher than concomitantly measured net fatty acid and glycerol release from subcutaneous, abdominal adipose tissue $[17,22]$. Data obtained by the microdialysis technique do not allow measurement of the fatty acid concentration and release. They are also difficult to interpret, because quantitation is based on several assumptions [23, 24].

The weaknesses of the present study are: (i) the low number of experimental subjects, (ii) the lack of a proper reference group. However, as emphasised in a recent study [2], it is difficult to find healthy subjects who are simultaneously matched for age, body composition and physical fitness. For this reason we compared our results with those previously obtained in young, healthy, non-obese subjects $[10,17]$. The groups are comparable with regard to relative exercise intensity and duration, although the absolute amount of exercise was about three-times greater in the healthy subjects.

Traditionally the release of glycerol from adipose tissue has been assumed to reflect the rate of intracellular lipolysis, as glycerol can only be re-used to a very limited extent in the adipocytes, owing to the very low activity of the enzyme glycerokinase [25, 26]. If all the fatty acids released by lipolysis in the adipocytes were released to the blood concomitantly with glycerol, the fatty acid:glycerol release ratio should be 3 . In the pre-exercise rest period the ratio was about 2.4, similar to that in healthy subjects [10, 17] (Fig. 1d). However, it decreased to 1.8 during exercise, increasing to the pre-exercise value 1.5 hours after exercise. This contrasts with the increase seen in healthy subjects during exercise [10]. On the other hand, the ratio in the initial post-exercise recovery period (0-60 minutes) was much larger than 3 .

The amount of fatty acids released from adipose tissue is determined primarily by the lipolytic rate and secondarily by the ability of the blood perfusing the adipose tissue to transport fatty acids away from the tissue $[27,28]$. Thus, the reduction in the fatty acids:glycerol release ratio during exercise shows that there is a discrepancy between the increase in the lipolytic rate and the concomitant increase in adipose tissue blood flow, implying that the fatty acid release becomes restricted. In young, healthy subjects adipose tissue blood flow increases about three-fold during prolonged exercise of moderate intensity [12]. In the patients we studied, the blood flow increase was only about $50 \%$, and the absolute increase, amounting to about $0.5 \mathrm{ml} \cdot 100 \mathrm{~g}^{-1} \cdot \mathrm{min}^{-1}$, was five to six times smaller than the increase generally seen in healthy, lean subjects (Fig. 1a). It remains to be shown whether this is a protective mechanism preventing the concentration of circulating fatty acids from increasing to toxic levels, or whether it is a blunted flow response comparable to that described in obese subjects postprandially [29].

The high fatty acid:glycerol release ratios found 30 and 60 minutes post-exercise (4.8 and 7.1) indicate that some of the fatty acids liberated by lipolysis during exercise had been retained in the tissue and released post-exercise. It has previously been suggested that fatty acids are to some extent trapped intracellu- 
larly in adipose tissue during exercise in healthy, normal-weight subjects [30], but the release of excess fatty acid seems to be larger and of longer duration in diabetic patients [10,17] (Fig. 1d). As described by us [10, 17], lipolysis and fatty acid mobilisation in healthy subjects begin to increase again about one hour after exercise and stay increased for several hours. We did not observe a similar increase in the post-exercise recovery period in the present experiments (Fig. 1b,c). This could be due to the much lower exercise intensity applied in the present study. In our earlier study [10], we found that exercise at $60 \%$ of peak power output resulted in a significantly higher post-exercise lipid mobilisation than exercise at $40 \%$ of peak power output. However, the mechanism that causes the post-exercise increase in lipid mobilisation has not been explained.

It has been a matter of debate whether lipolysis and fatty acid mobilisation from adipose tissue are enhanced in insulin-resistant states. Findings have been divergent, possibly owing to different ways of expressing the lipolytic and fatty acid mobilisation rates, e.g. per adipose tissue mass, cell number, cell size etc., as reviewed by Lewis et al. [31]. In the present experiment, the regional lipolytic rate $(\sim$ net glycerol release rate) per unit adipose tissue weight was not larger in the patients, either during rest or during exercise, than in healthy young subjects (Fig. 1b). From this perspective, therefore, insulin resistance does not result in enhanced lipolysis. Recently it has been proposed that resting whole-body fatty acid mobilisation correlates better to resting energy expenditure than to lean body mass or fat mass [32]. The resting energy expenditure was not increased in the present subjects, while their total fat mass was about three-fold larger than that of the subjects studied previously $[10,17]$. Thus, assuming that the subcutaneous, abdominal adipose tissue represents the average adipose tissue, the whole-body adipose tissue lipolytic rate was much larger in these present patients than in healthy subjects. It therefore seems that the total adipose tissue is insulin resistant, since lipolysis is stimulated in excess of need during rest and especially during exercise.

The plasma glucose concentration decreased steadily in our subjects during exercise, in accordance with previous findings $[5,6,9,33]$. In contrast to one of these studies [33], we found a further decrease in the plasma glucose concentration in the post-exercise recovery period. Splanchnic glucose production increased significantly during exercise, while tending to decrease to a level below the pre-exercise level in the post-exercise period $(p=0.16)$. In light of the decreasing arterial glucose concentration, hepatic glucose output was not sufficient to match glucose utilisation. The uptake of gluconeogenic precursors (glycerol and lactate) increased significantly during exercise, but was not increased post-exercise.
In spite of the fact that arterial fatty acid concentration was increased in the early post-exercise phase, we were unable to show significant changes in splanchnic fatty acid uptake, although it increased by about $25 \%$ on average against the pre-exercise level $(p=0.26)$. The increase in the splanchnic output of ketone bodies post-exercise indicates that a larger fraction of the fatty acids taken up in the liver was directed to partial or total oxidation instead of to re-esterification and VLDL assembly. The splanchnic energy expenditure during rest was greater in absolute and in relative terms than that of normal healthy subjects. In normal subjects, splanchnic oxygen consumption is about $2.5 \mathrm{mmol} / \mathrm{min}$, which corresponds to 20 to $25 \%$ of whole-body oxygen consumption [16, 17, 34], as opposed to about $33 \%$ in the present patients. The splanchnic oxygen consumption found in our experiments is similar to that found in other Type 2 diabetic patients in [9]. Judged from the uptake of gluconeogenic precursors, it is unlikely that the high oxygen consumption can be explained by increased gluconeogenesis. Similarly, although ketogenesis was about two-fold higher than in normal, healthy subjects [17], this higher value can only account for about $10 \%$ of the difference in oxygen consumption. One possible explanation is that the increase in splanchnic oxygen consumption was due to increased oxidative stress to the liver [35].

Conclusion. In untrained, overweight subjects with Type 2 diabetes regional subcutaneous, abdominal adipose tissue lipolysis is not different from lipolysis in normal-weight, healthy subjects. Exercise stimulates adipose tissue lipolysis, but in abdominal, subcutaneous adipose tissue the lipolytic rate increases much more than the fatty acid release rate, probably due to an insufficient increase in adipose tissue blood flow. This implies that a high fraction of the fatty acids liberated by lipolysis in the adipocytes cannot be released to the blood during exercise. On the other hand, fatty acids are being released to the blood in excess of lipolysis during the first hour post-exercise. The exercise-induced increase in splanchnic glucose release is lower than the increase in whole-body glucose utilisation, resulting in a decrease in blood glucose concentration during exercise. The blood glucose concentration continues to decrease for at least up to 3 hours during post-exercise recovery, showing that there is also a discrepancy between endogenous glucose production and glucose utilisation in the postexercise period. Due to the low number of subjects studied in our experiments, further studies will be necessary to elucidate whether the present findings are due to the diabetic state itself, and to discover the mechanisms responsible (i) for the blunted increase in adipose tissue blood flow during exercise, and (ii) for the low endogenous glucose production during, and especially after, exercise. 
Acknowledgements. This study was supported by grants from the Novo Nordic Foundation, the John and Birthe Meyer Foundation, the Danish Medical Research Council (22-01-0235) and the Danish Heart Foundation (02-2-3-34-22016).

\section{References}

1. Blaak EE, Aggel-Leijssen DP, Wagenmakers AJ, Saris WH, van Baak MA (2000) Impaired oxidation of plasmaderived fatty acids in type 2 diabetic subjects during moderate-intensity exercise. Diabetes 49:2102-2107

2. Borghouts LB, Wagenmakers AJ, Goyens PL, Keizer HA (2002) Substrate utilization in non-obese Type II diabetic patients at rest and during exercise. Clin Sci (Lond) 103:559-566

3. Londos C, Brasaemle DL, Schultz CJ et al. (1999) On the control of lipolysis in adipocytes. Ann NY Acad Sci 892:155-168

4. Lam TK, Carpentier A, Lewis GF, Werve G van de, Fantus IG, Giacca A (2003) Mechanisms of the free fatty acidinduced increase in hepatic glucose production. Am J Physiol Endocrinol Metab 284:E863-E873

5. Minuk HL, Vranic M, Marliss EB, Hanna AK, Albisser AM, Zinman B (1981) Glucoregulatory and metabolic response to exercise in obese noninsulin-dependent diabetes. Am J Physiol 240:E458-E464

6. Schneider SH, Khachadurian AK, Amorosa LF, Gavras H, Fineberg SE, Ruderman NB (1987) Abnormal glucoregulation during exercise in type II (non-insulin-dependent) diabetes. Metabolism 36:1161-1166

7. Kang J, Robertson RJ, Hagberg JM et al. (1996) Effect of exercise intensity on glucose and insulin metabolism in obese individuals and obese NIDDM patients. Diabetes Care 19:341-349

8. Colberg SR, Hagberg JM, McCole SD, Zmuda JM, Thompson PD, Kelley DE (1996) Utilization of glycogen but not plasma glucose is reduced in individuals with NIDDM during mild-intensity exercise. J Appl Physiol 81:2027-2033

9. Martin IK, Katz A, Wahren J (1995) Splanchnic and muscle metabolism during exercise in NIDDM patients. Am J Physiol 269:E583-E590

10. Mulla NA, Simonsen L, Bülow J (2000) Post-exercise adipose tissue and skeletal muscle lipid metabolism in humans: the effects of exercise intensity. J Physiol 524:919-928

11. Simonsen L, Bülow J, Madsen J (1994) Adipose tissue metabolism in humans determined by vein catheterization and microdialysis techniques. Am J Physiol 266:E357E365

12. Bülow J (1983) Adipose tissue blood flow during exercise. Dan Med Bull 30:85-100

13. Simonsen L, Enevoldsen LH, Bülow J (2003) Determination of adipose tissue blood flow with local ${ }^{133} \mathrm{Xe}$ clearance. Evaluation of a new labelling technique. Clin Physiol Funct Imaging 23:320-323

14. Henriksen JH, Winkler K (1987) Hepatic blood flow determination. A comparison of 99-Tc-diethyl-IDA and indocyanine green as hepatic blood flow indicators in man. J Hepatol 4:66-70

15. Bülow J, Simonsen L, Wiggins D et al. (1999) Co-ordination of hepatic and adipose tissue lipid metabolism after oral glucose. J Lipid Res 40:2034-2043

16. Simonsen L, Ryge C, Bülow J (1995) Glucose-induced thermogenesis in splanchnic and leg tissues in man. Clin Sci (Lond) 88:543-550
17. Hall G van, Bülow J, Sacchetti M, Al Mulla N, Lyngso D, Simonsen L (2002) Regional fat metabolism in human splanchnic and adipose tissues; the effect of exercise. J Physiol 543:1033-1046

18. Basu A, Basu R, Shah P, Vella A, Rizza RA, Jensen MD (2001) Systemic and regional free fatty acid metabolism in type 2 diabetes. Am J Physiol Endocrinol Metab 280:E1000-E1006

19. Jansson PA, Smith U, Lönnroth P (1995) Microdialysis assessment of adipose tissue metabolism in post-absorptive obese NIDDM subjects. Eur J Clin Invest 25:584-589

20. Blaak EE, Kemerink GJ, Pakbiers MT, Wolffenbuttel BH, Heidendal GA, Saris WH (1999) Microdialysis assessment of local adipose tissue lipolysis during beta-adrenergic stimulation in upper-body-obese subjects with type II diabetes. Clin Sci (Lond) 97:421-428

21. Merwe MT van der, Schlaphoff GP, Crowther NJ et al. (2001) Lactate and glycerol release from adipose tissue in lean, obese, and diabetic women from South Africa. J Clin Endocrinol Metab 86:3296-3303

22. Coppack SW, Persson M, Judd RL, Miles JM (1999) Glycerol and nonesterified fatty acid metabolism in human muscle and adipose tissue in vivo. Am J Physiol 276:E233-E240

23. Stallknecht B, Madsen J, Galbo H, Bülow J (1999) Evaluation of the microdialysis technique in the dog fat pad. Am J Physiol 276:E588-E595

24. Arner P, Bülow J (1993) Assessment of adipose tissue metabolism in man: comparison of Fick and microdialysis techniques. Clin Sci (Lond) 85:247-256

25. Koschinsky T, Gries FA (1971) [Glycerol kinase and lipolysis in human adipose tissue in relation to relative body weight] (in German). Hoppe Seylers Z Physiol Chem 352:430-432

26. Wolfe RR, Klein S, Carraro F, Weber JM (1990) Role of triglyceride-fatty acid cycle in controlling fat metabolism in humans during and after exercise. Am $\mathrm{J}$ Physiol 258:E382-E389

27. Bülow J, Madsen J (1981) Influence of blood flow on fatty acid mobilization form lipolytically active adipose tissue. Pflugers Arch 390:169-174

28. Madsen J, Bülow J, Nielsen NE (1986) Inhibition of fatty acid mobilization by arterial free fatty acid concentration. Acta Physiol Scand 127:161-166

29. Jansson PA, Larsson A, Lönnroth PN (1998) Relationship between blood pressure, metabolic variables and blood flow in obese subjects with or without non-insulin-dependent diabetes mellitus. Eur J Clin Invest 28:813-818

30. Hodgetts V, Coppack SW, Frayn KN, Hockaday TD (1991) Factors controlling fat mobilization from human subcutaneous adipose tissue during exercise. J Appl Physiol 71:445-451

31. Lewis GF, Carpentier A, Adeli K, Giacca A (2002) Disordered fat storage and mobilization in the pathogenesis of insulin resistance and type 2 diabetes. Endocr Rev 23:201-229

32. Nielsen S, Guo Z, Albu JB, Klein S, O'Brien PC, Jensen MD (2003) Energy expenditure, sex, and endogenous fuel availability in humans. J Clin Invest 111:981-988

33. Giacca A, Groenewoud Y, Tsui E, McClean P, Zinman B (1998) Glucose production, utilization, and cycling in response to moderate exercise in obese subjects with type 2 diabetes and mild hyperglycemia. Diabetes 47:1763-1770

34. Simonsen L, Coker R, Mulla AL, Kjaer M, Bülow J (2002) The effect of insulin and glucagon on splanchnic oxygen consumption. Liver 22:459-466

35. Leverve X (2003) Hyperglycemia and oxidative stress: complex relationships with attractive prospects. Intensive Care Med 29:511-514 